\title{
Adaptive Neuro-Fuzzy Inference System-Particle Swarm Optimization Based Stability Maintenance of Power System Networks
}

\author{
${ }^{1}$ R. Latha and ${ }^{2} J$. Kanakaraj \\ ${ }^{1}$ Department of Instrumentation and Control Engineering, \\ ${ }^{2}$ Department of Electrical and Electronics Engineering, \\ PSG College of Technology, Coimbatore, India
}

Received 2013-05-27, Revised 2013-05-29; Accepted 2013-07-05

\begin{abstract}
During faulty condition voltage instability is one of the major crisis in power system networks. This study proposes a hybrid learning algorithm to improve the stability performance of a power system with Distributed Generations (DGs). Here the distribution system stability is maintained with reduced power loss using an Adaptive Neuro-Fuzzy Inference Systems (ANFIS) and Particle Swarm Optimization (PSO) techniques. In this study distributed generations is considered as several types of DGS connected together which is called as Microgrid (MG). Initially ANFIS is trained by instability parameters to give the optimal power capacity of the microgrid and then PSO algorithm is applied to find the optimum bus for connecting microgrid in the system. The effective improvements in voltage profile and reduction in power loss of the proposed ANFIS-PSO controller is tested on IEEE-30 bus system and has been presented with few comparative results.
\end{abstract}

Keywords: Distributed Generation, Microgrid, Adaptive Neuro-Fuzzy Inference Systems (ANFIS), Particle Swarm Optimization (PSO), Stability

\section{INTRODUCTION}

Distribution networks are the final connection between the transmission networks and electricity consumers. The performance of a distribution system and quality of the service provided are calculated in terms of frequency disruption and also the maintenance of suitable voltage levels at the customers' locality. The quality of supply can significantly be enhanced, by integrating reliability considerations in the system design as well as assigning the system expansion planning, operation and maintenance. The distribution system provides more opportunities for smart grid concepts.

Current technological, environmental, economical and social trends in electric utility systems have paid attention to microgrid concepts (Hatziargyriou et al.,
2007; Lasseter and Piagi, 2004). Combination of many small energy sources is the microgrid which is one of the decentralized energy generation system. Commonly, microgrids are capable of islanding from the major grid to afford uninterruptible power to the local loads. A large selection of energy sources together with gas turbines, photovoltaics, wind turbines and batteries may be incorporated into the microgrid system. To generate continuous power supply through abnormal condition, microgrid is utilized to trim down the total power losses in the system. Microgrid loses its steady condition if any fault occurs in the system. Microgrid needs to produce power based on the fault condition in order to maintain the system stability (Lasseter and Piagi, 2006; Lasseter, 2011; Singh et al., 2008).

Corresponding Author: R. Latha, Department of Instrumentation and Control Engineering, PSG College of Technology, Coimbatore, India 
In the literature, several techniques have been developed to minimize the power loss and to improve the voltage profile. Acharya et al. (2006) have proposed the method to determine the appropriate size of DG units. In previous works, intelligent techniques like fuzzy logic, neural networks, genetic algorithm and particle swarm optimization are used for distributed generation placements and estimation of distribution capacity (Kayal and Chanda, 2013; Kalaivani and Kamaraj, 2012; Aref et al., 2012), but they are being slow in convergence. The adaptivness of such methods are not substantial at dissimilar steadiness level.

In our previous research, fuzzy logic is used to identify whether the system is normal or abnormal condition and neural network technique is used to determine the amount of power to be generated according to the system's condition. ANN is trained from the dataset generated by PSO. In order to use learning capability of the neural network, it is combined with fuzzy systems. This technique can be used to utilize the membership functions so that we can easily integrate prior knowledge into the system and can substantially shorten the learning process. This article investigates stability enhancement of power systems with various types of distributed generations by using hybrid approach. The proposed hybrid approach employs an Adaptive Neuro-Fuzzy Inference System (ANFIS) and Particle Swarm Optimization (PSO) techniques. ANFIS technique is used to determine the optimum power generated by the microgrid and PSO technique is used to find the location of the bus to which the microgrid is to be connected. With the influences of both ANFIS and PSO techniques the reduction in power loss and improvements in voltage profile are obtained.

The organization of this study is as follows: Following the introduction, stability condition is determined by calculating Voltage Stability Indicator (VSI) is described. In Section 3, the ANFIS and PSO algorithms are discussed. The simulated results are illustrated in Section 4. Conclusions are presented in Section 5.

\section{MATERIALS AND METHODS}

In this study, Adaptive Neuro-Fuzzy Inference Systems (ANFIS) and Particle Swarm Optimization (PSO) techniques are projected to uphold the steadiness of power system with distributed generations. Here the distributed generations are considered as microgrid which consists of a cluster of various types of distributed generations. The microgrid with rated capacity is connected in exact location in order to minimize the total power loss. The proposed method identifies the weak buses from the evaluation of Voltage Stability Index (VSI). ANFIS is trained from the input-output data generated by load flow analysis using NewtonRaphson method. PSO algorithm is used to identify the bus which has maximum power loss. That bus is considered as optimum location to connect the microgrid to generate enough power based on the system condition. The proposed algorithm is tested on IEEE-30 bus system. The results obtained using hybrid approach provide minimum real power loss and show improvement in voltage profile compared with existing ANN based approach. The factors which are related to the stability of the system like voltage stability index, real and reactive power and power loss are calculated in the following sections.

\subsection{Voltage Stability Index}

Voltage Stability Index (VSI) is a quantitative measurement to illustrate the system's stability condition. The VSI is generated from the basic power flow equation and/or energy functions. The values of VSI are distinctly different in abnormal condition compared to normal condition of a power system (Rui, 2009). The voltage instability of the system is reduced by adding the microgrids in the distribution system. The proposed method identifies the weak buses from the evaluation of the voltage difference between the reference voltage and the slack bus voltage. The error voltage equation of the system is given in Equation (1):

$\mathrm{V}_{\mathrm{EE}}=\mathrm{V}_{\mathrm{SB}}-\mathrm{Z}_{\text {eqt }}\left[\frac{\mathrm{P}_{\mathrm{mm}}-\mathrm{jQ} \mathrm{Qm}_{\mathrm{m}}}{\mathrm{V}_{\mathrm{mm}}}\right]$

where, $\mathrm{V}_{\mathrm{EE}}$ is the deviated voltage, $\mathrm{V}_{\mathrm{mm}}$ is the $\mathrm{mm}^{\text {th }}$ bus voltage $\mathrm{mm}=1,2,3 \ldots 1$. The weak buses can be identified by the Equation (1). The standard voltage of the slack bus $\left(V_{\mathrm{SB}}\right)$ is 1 p.u, which is used for determining change in voltage. The voltage stability of the system is given in Equation (2):

$$
\mathrm{VSI}_{\mathrm{pp}}=\frac{\left[\sum_{\mathrm{mm}-1}^{\mathrm{t}}\left(\mathrm{V}_{\mathrm{EE}}\right)^{2}\right]^{1 / 2}}{\sqrt{1}}
$$

where, $\mathrm{VSI}_{\mathrm{pp}}$ is the Voltage Stability Index of the pp bus, $\mathrm{V}_{\mathrm{EE}}$ is the error voltage, 1 is the number of nodes. The calculated index shows the system's stability condition 
and can be used to estimate the systems operating states. The voltage stability index of the node is maintained at the range of 1 p.u. If the node voltage crosses the constraints, it is identified as weak node. That node is selected for microgird placement. In the proposed system the voltage profile is calculated for every node.

\subsection{Load Flow Analysis}

A load flow analysis can be utilized to determine total transmission losses in a system (Attous and Labbi, 2009). In this proposed method the load flow calculation between the buses is calculated using the N-R method. The real and reactive power flows between the buses are calculated by Equation (3) and (4):

$$
\begin{aligned}
& \mathrm{P}_{\mathrm{mm}}=\mathrm{V}_{\mathrm{mm}} \sum_{\mathrm{nn}=1}^{\mathrm{N}_{\mathrm{B}}} \mathrm{Y}_{\mathrm{mmnn}} * \mathrm{~V}_{\mathrm{nn}} * \cos \left(\alpha_{\mathrm{mm}}-\alpha_{\mathrm{nn}}-\delta_{\mathrm{mmnn}}\right)=0 \\
& \mathrm{Q}_{\mathrm{mm}}=\mathrm{V}_{\mathrm{mm}} \sum_{\mathrm{nn}=1}^{\mathrm{N}_{\mathrm{B}}} \mathrm{Y}_{\mathrm{mmnn}} * \mathrm{~V}_{\mathrm{nn}} * \sin \left(\alpha_{\mathrm{mm}}-\alpha_{\mathrm{nn}}-\delta_{\mathrm{mmnn}}\right)=0
\end{aligned}
$$

where, $\mathrm{P}_{\mathrm{mm}}$ is the power of the mm bus, $\mathrm{Q}_{\mathrm{mm}}$ is the reactive power of the mm bus, $N_{B}$ is the total number of buses, $\mathrm{V}_{\mathrm{mm}}$ and $\mathrm{V}_{\mathrm{nn}}$ are the voltage of $\mathrm{mm}$ and $\mathrm{nn}$ buses respectively, $\alpha_{\mathrm{mm}}$ and $\alpha_{\mathrm{nn}}$ is the angle between mmand $\mathrm{nn}$ buses respectively, $\mathrm{Y}_{\mathrm{mmnn}}$ and $\delta_{\mathrm{mmnn}}$ is the magnitude and angle of the entry in the $\mathrm{Y}$ - bus matrix. The generated power must satisfy the total demand of the system and the total loss of the system. The apparent power is the combination of real and reactive power and is given in Equation (5):

$$
\mathrm{S}=\sum_{\mathrm{n}=1}^{\mathrm{N}_{\mathrm{G}}}\left(\mathrm{P}_{\mathrm{Gn}}+\mathrm{jQ}_{\mathrm{Gn}}\right)=\sum_{\mathrm{n}=1}^{\mathrm{N}_{\mathrm{B}}}\left[\left(\mathrm{P}_{\mathrm{Dn}}+\mathrm{j} \mathrm{Q}_{\mathrm{Dn}}\right)+\left(\mathrm{P}_{\mathrm{Ln}}+\mathrm{j} \mathrm{Q}_{\mathrm{Ln}}\right]\right.
$$

where, $\mathrm{P}_{\mathrm{Gn}}$ and $\mathrm{Q}_{\mathrm{Gn}}$ are the real and reactive power generated in $1,2, . . \mathrm{N}_{\mathrm{G}}$ units, $\mathrm{P}_{\mathrm{Dn}}$ and $\mathrm{Q}_{\mathrm{Dn}}$ are the active and reactive power demand in the $1,2 \ldots \mathrm{N}_{\mathrm{B}}$ buses, $\mathrm{P}_{\mathrm{Ln}}$ and $\mathrm{Q}_{\mathrm{Ln}}$ are the real and reactive power loss in the $1,2 \ldots \mathrm{N}_{\mathrm{B}}$ buses. The power flow in the transmission line must be restricted within their respective inequality constraints are given in Equation (6) and (7):

$$
\begin{aligned}
& \mathrm{P}_{\mathrm{Gn}}{ }^{\text {min }} \leq \mathrm{P}_{\mathrm{Gn}} \leq \mathrm{P}_{\mathrm{Gn}}{ }^{\max } ; \mathrm{n}=1,2 \ldots \mathrm{N}_{\mathrm{G}} \\
& \mathrm{Q}_{\mathrm{Gn}}{ }^{\text {min }} \leq \mathrm{Q}_{\mathrm{Gn}} \leq \mathrm{Q}_{\mathrm{Gn}}{ }^{\text {max }} ; \mathrm{n}=1,2 \ldots \mathrm{N}_{\mathrm{G}}
\end{aligned}
$$

The power loss is the important factor in the stability of distribution system which affects the optimum power flow of the distribution system. The real and the reactive power loss of the distribution system are given by Equation (8) and (9):

$$
\begin{aligned}
& \mathrm{P}_{\mathrm{LL}}=\sum_{\mathrm{mm}=1}^{\mathrm{N}_{\mathrm{B}}} \sum_{\mathrm{nn}=1}^{\mathrm{N}_{\mathrm{B}}}\left[\begin{array}{c}
\left.\left.\mathrm{A}_{\mathrm{mmnnn}}\left(\mathrm{P}_{\mathrm{mm}} \mathrm{P}_{\mathrm{mn}}+\mathrm{Q}_{\mathrm{mm}} \mathrm{Q}_{\mathrm{nn}}\right)+\mathrm{P}_{\mathrm{mm}} \mathrm{Q}_{\mathrm{nn}}\right)\right] \\
\left.\mathrm{P}_{\mathrm{m}}\right)
\end{array}\right. \\
& \mathrm{Q}_{\mathrm{LL}}=\sum_{\mathrm{mm}=1}^{\mathrm{N}_{\mathrm{B}}} \sum_{\mathrm{nn}=1}^{\mathrm{N}_{\mathrm{B}}}\left[\mathrm { D } _ { \mathrm { mmnn } } \left(\mathrm{C}_{\mathrm{mmmn}}\left(\mathrm{P}_{\mathrm{mm}} \mathrm{P}_{\mathrm{nn}}+\mathrm{Q}_{\mathrm{mm}} \mathrm{Q}_{\mathrm{mm}}\right)+\right.\right.
\end{aligned}
$$

Where:

$$
\begin{aligned}
& \mathrm{A}_{\mathrm{mmnn}}=\frac{\mathrm{R}_{\mathrm{mmnn}}}{\left|\mathrm{V}_{\mathrm{mm}}\right|\left|\mathrm{V}_{\mathrm{nn}}\right|} \cos \left(\alpha_{\mathrm{mm}}-\alpha_{\mathrm{nn}}\right) \\
& \mathrm{B}_{\mathrm{mmnn}}=\frac{\mathrm{R}_{\mathrm{mmnn}}}{\left|\mathrm{V}_{\mathrm{mm}}\right|\left|\mathrm{V}_{\mathrm{nn}}\right|} \sin \left(\alpha_{\mathrm{mm}}-\alpha_{\mathrm{nn}}\right) \\
& \mathrm{C}_{\mathrm{mmnn}}=\frac{\mathrm{X}_{\mathrm{mmnn}}}{\left|\mathrm{V}_{\mathrm{mm}}\right|\left|\mathrm{V}_{\mathrm{nn}}\right|} \cos \left(\alpha_{\mathrm{mm}}-\alpha_{\mathrm{nn}}\right) \\
& \mathrm{D}_{\mathrm{mmnn}}=\frac{\mathrm{X}_{\mathrm{mmnn}}}{\left|\mathrm{V}_{\mathrm{mm}}\right|\left|\mathrm{V}_{\mathrm{nn}}\right|} \sin \left(\alpha_{\mathrm{mm}}-\alpha_{\mathrm{nn}}\right)
\end{aligned}
$$

where, $A_{m m n n}, B_{m m n n}, C_{m m n n}$ and $D_{m m n n}$ are the loss coefficients, $\alpha_{\mathrm{mm}}$ and $\alpha_{\mathrm{nn}}$ are load angles at the buses, $\mathrm{R}_{\mathrm{mmnn}}$ and $\mathrm{X}_{\mathrm{mmnn}}$ are the real and reactive components of the impedance bus matrix.

\subsection{ANFIS and PSO Algorithm}

In building intelligent systems, fuzzy systems and neural networks are natural complementary tools (Mashrei, 2012; Fraile-Ardanuy and Zufiria, 2005). Neural networks are low-level computational structures that perform well when dealing with raw data and fuzzy logic deals with reasoning on a higher level. But, fuzzy systems lack the capability to learn and cannot regulate themselves. A neuro-fuzzy system is, actually a neural network that is functionally equivalent to a fuzzy inference model. To build a fuzzy inference model with known input/output data, the neuro adaptive learning techniques are used. This technique provides a method for the fuzzy modelling procedure to learn information about a data set, in order to compute the membership function parameters to track the input/output data.

An Adaptive Neuro-Fuzzy Inference System (ANFIS) proposed by Mashrei (2012) is a five-layer feed-forward neural network, which contains fuzzy layer, 
product layer, normalized layer, defuzzify layer and a total output layer. An ANFIS uses a hybrid learning algorithm that syndicates the least-squares estimator and the gradient descent method (Jang, 1993; Mashrei, 2012; Fraile-Ardanuy and Zufiria, 2005). The proposed ANFIS output is a Sugeno-type system and it has unity weight for each rule.

The ANFIS uses a hybrid learning algorithm (Rui, 2009; Kothari and Nagrath, 2006) and its structure is given in Fig. 1. In this study ANFIS is trained from the input and output data generated by load flow analysis. The inputs to ANFIS are voltage, power loss and the change in values of voltage and power loss. $\mathrm{x}=\left[\mathrm{V}, \mathrm{P}_{\mathrm{LL}}\right]$ and $\mathrm{y}=\left[\Delta \mathrm{V}, \Delta \mathrm{P}_{\mathrm{LL}}\right]$. Depending on the errors, allocation of microgrid capacity has been predicted.

With two fuzzy a common rule set is developed for a zero-order Sugeno fuzzy model and is given below:

- Rule1: If $\mathrm{x}$ is $\mathrm{C}_{1}$ and $\mathrm{y}$ is $\mathrm{D}_{1}$ then $\mathrm{f}_{1}=\mathrm{m}_{1} \mathrm{x}+\mathrm{n}_{1} \mathrm{y}+\mathrm{k}_{1}$

- Rule2: If $x$ is $C_{2}$ and $y$ is $D_{2}$ then $f_{2}=m_{2} x+n_{2} y+k_{2}$

where $\mathrm{m}_{1}, \mathrm{~m}_{2}, \mathrm{n}_{1}, \mathrm{n}_{2}, \mathrm{k}_{1}$ and $\mathrm{k}_{2}$ are the linear parameters, $C_{1}, C_{2}, D_{1}$ and $D_{2}$ are the non linear parameters. The five layers of the proposed system are fuzzy layer, product layer, normalized layer, defuzzify layer and total output layer.

In order to minimize the total power loss of the load bus, suitable bus is identified to connect the microgird using Particle Swarm Optimization (PSO) algorithm. Hence the distribution system stability has been maintained by optimal capacity of microgrid. PSO is a modern heuristic search method motivated from the simulation of the behavior of social systems such as fish schooling and birds flocking (Aref et al., 2012). Using PSO algorithm the bus which is having biggest loss reduction during abnormal condition is identified as given in Equation (10). The microgrid connected to the bus which is identified has maximum power loss is selected to generate enough power based on system condition:

$\varphi=\operatorname{Max} \sum_{i=1}^{N_{B}} P_{L L}(i)$

where, $P_{L L}(i)$ is real power loss of the $i^{\text {th }}$ bus and $\mathrm{N}_{\mathrm{LB}}$ is the number of load buses. The PSO algorithm steps are given below:

Step1: Initialize the power loss and the real power and voltage of all the buses.

Step2: Calculate the fitness function of the proposed system for every generator shut down conditions. The fitness is the real power difference between before shutdown the generator and after shutdown the generator.

Step3: Set iteration count $\mathrm{I}=1$.

Step4: To find the bus, which have the maximum real power variation; it can be determined by the real power difference between before shutdown the generator and after shutdown the generator. The high real power deviation bus consists of high power loss. The maximum real power deviation occurred bus is known as $\mathrm{P}_{\text {best }}$.

Step5: Modify the current position.

Step6: Select the $\mathrm{G}_{\text {best }}$ among the updated positions. If the iteration count reaches maximums go to the next step7 otherwise set the iteration count $\mathrm{I}=$ $\mathrm{I}+1$, then go to step 4 and repeat the procedure.

Step7: The particular bus has been selected for the optimal location (Aref et al., 2012).

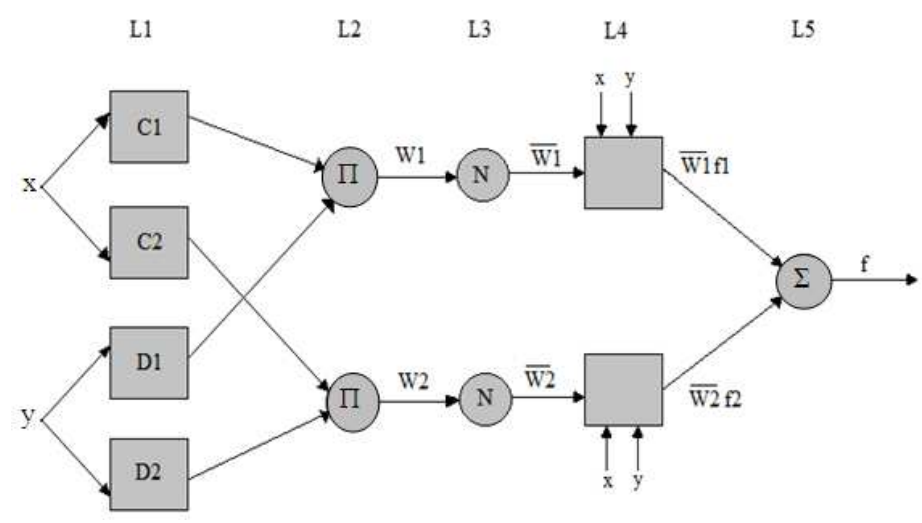

Fig. 1. ANFIS structure 


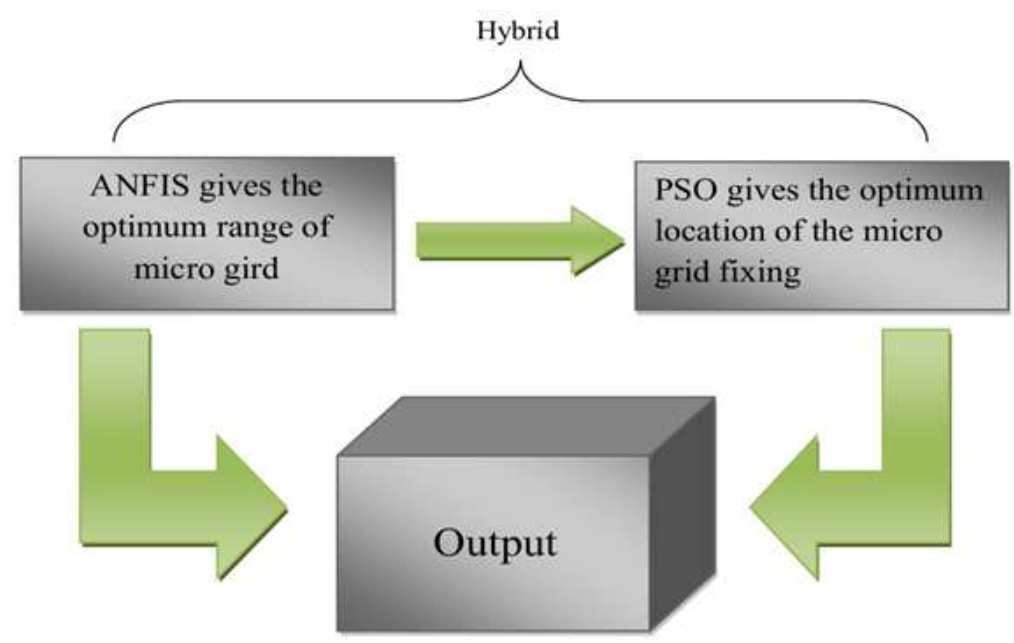

Fig. 2. Proposed system flow diagram

Once the process is completed the bus which has a maximum power loss is idenfied. That bus is the optimum place to connect the microgrid to maintain the stability of the distribution system. The proposed system operation is shown in Fig. 2.

\section{RESULTS AND DISCUSSION}

The proposed methodology is tested on IEEE-30 bus system. The structure of IEEE-30 bus system is shown in Fig. 3. In the test system, bus 1 is considered as slack bus and Base MVA is 100 MVA. The bus 2, 5, 13, 22 and 27 are generator bus and all the other buses are load buses. Real power loss during faulty condition for IEEE-30 bus system is given in Table 1. It shows the affected buses during the operation of IEEE-30 bus system and the optimum location to connect the microgrid and the capacity of microgrid to dissolve the instability condition. From the Table 1, it is observed that the power loss for normal condition is $10.8049 \mathrm{MW}$, during the instability period it will be raised at the level 14.7262 MW and power loss of the load bus is minimized at 8.6968 MW. Figure 4 illustrates power loss of the proposed method in various conditions like before connecting microgrid and after connecting the microgrid.

Voltage stability of the IEEE-30 bus system has been illustrated in the Table 2 which has the performance comparison of the proposed method and the existing neural network technique. During fault, the affected buses are given in the table is $24,12,15$, 21,14 and 17 . In these buses the voltage stability using the existing method is compared with the proposed method. For existing technique the best voltage level is $1.0355 \mathrm{p} . \mathrm{u}$ but for the proposed hybrid method which is maintained into 1.0018 p.u. The voltage profile of both existing method and proposed hybrid method is shown in Fig. 5. The results illustrate the improvement in voltage profile (nearly 1 p.u) by proposed method compared with existing method.

The load buses are 2, 3, 4, 5, 7, 8, 10, 12, 14, 18, 20, 21, 23 and 26 and the normal total power loss using conventional N-R method is 10.8049 MW. But, in the proposed system, the total power loss of the system is reduced to $8.689 \mathrm{MW}$. Comparison of power loss of IEEE-30 bus system during fault time and after connecting microgrid is obtained from both conventional N-R method and proposed method is given in Table 3 and the corresponding graph is given in Fig. 6.

These analysis show that the proposed method maintained the better voltage stability and total power loss of the system, which is competent over the other techniques. In the present work, the voltage profile is increased for all the buses and a real power loss is reduced by $1.2 \%$. 
Table 1. The total power loss with and without microgrid for IEEE-30 bus system

\begin{tabular}{|c|c|c|c|c|c|c|}
\hline \multirow[b]{2}{*}{$\begin{array}{l}\text { Abnormal } \\
\text { load } \\
\text { bus no. }\end{array}$} & \multicolumn{2}{|l|}{ Before fault } & \multicolumn{4}{|l|}{ After fault } \\
\hline & $\begin{array}{l}\text { Normal Power } \\
\text { loss of bus } \\
\text { MW }\end{array}$ & $\begin{array}{l}\text { Distortion time } \\
\text { power loss } \\
\text { MW }\end{array}$ & $\begin{array}{l}\text { Optimum bus } \\
\text { location for } \\
\text { connecting MG } \\
\text { MW }\end{array}$ & $\begin{array}{l}\text { Capacity of MG } \\
\text { MW }\end{array}$ & $\begin{array}{l}\text { Power loss } \\
\text { before } \\
\text { connecting MG } \\
\text { MW }\end{array}$ & $\begin{array}{l}\text { Power loss after } \\
\text { connecting MG } \\
\text { MW }\end{array}$ \\
\hline 2 & 10.8049 & 14.7262 & 24 & 27.9800 & 11.020 & 10.6799 \\
\hline 3 & & & 12 & 15.9399 & 11.075 & 10.1202 \\
\hline 4 & & & 24 & 27.9800 & 11.151 & 10.6799 \\
\hline 5 & & & 15 & 20.3872 & 11.437 & 10.4455 \\
\hline 7 & & & 8 & 10.8808 & 11.339 & 8.6891 \\
\hline 8 & & & 30 & 13.6698 & 11.411 & 10.3854 \\
\hline 10 & & & 7 & 9.8498 & 11.249 & 8.6968 \\
\hline 12 & & & 30 & 13.6698 & 11.169 & 10.3854 \\
\hline 14 & & & 15 & 20.3872 & 11.250 & 10.4455 \\
\hline 18 & & & 21 & 28.0452 & 11.344 & 9.6574 \\
\hline 21 & & & 14 & 18.8762 & 11.277 & 10.7541 \\
\hline 23 & & & 17 & 23.3723 & 11.298 & 10.3384 \\
\hline 26 & & & 30 & 13.6698 & 11.434 & 10.3854 \\
\hline
\end{tabular}

Table 2. Comparison of voltage profile between existing method and proposed method for IEEE 30-bus system

\begin{tabular}{|c|c|c|c|}
\hline \multirow[b]{2}{*}{$\begin{array}{l}\text { Optimum bus location } \\
\text { for the selection of MG } \\
\text { MW }\end{array}$} & \multirow[b]{2}{*}{$\begin{array}{l}\text { Voltage at the bus using Existing } \\
\text { ANN and Fuzzy based method } \\
\text { V }\end{array}$} & \multicolumn{2}{|c|}{ Voltage at the bus using proposed hybrid method } \\
\hline & & $\begin{array}{l}\text { Before connecting MG } \\
\mathrm{V}\end{array}$ & $\begin{array}{l}\text { After connecting MG } \\
\mathrm{V}\end{array}$ \\
\hline 24 & 1.0355 & 1.0154 & 1.0154 \\
\hline 12 & 1.0677 & 1.0568 & 1.0530 \\
\hline 15 & 1.0479 & 1.0347 & 1.0125 \\
\hline 21 & 1.0382 & 1.0216 & 1.0018 \\
\hline 14 & 1.0532 & 1.0408 & 1.0048 \\
\hline 17 & 1.0520 & 1.0313 & 1.0049 \\
\hline
\end{tabular}

Table 3. Total power loss reduction using proposed hybrid method for IEEE-30 bus system

\begin{tabular}{|c|c|c|c|}
\hline \multirow[b]{3}{*}{ Abnormal load bus no. } & \multicolumn{3}{|l|}{ Total power loss } \\
\hline & \multirow[b]{2}{*}{$\begin{array}{l}\text { Conventional N-R method } \\
\text { MW }\end{array}$} & \multicolumn{2}{|c|}{ Proposed hybrid method } \\
\hline & & $\begin{array}{l}\text { During fault time } \\
\text { MW }\end{array}$ & $\begin{array}{l}\text { After connecting MG } \\
\text { MW }\end{array}$ \\
\hline 2 & 10.8049 & 11.020 & 10.680 \\
\hline 3 & & 11.075 & 10.120 \\
\hline 4 & & 11.151 & 10.680 \\
\hline 5 & & 11.437 & 10.446 \\
\hline 7 & & 11.339 & 8.689 \\
\hline 8 & & 11.411 & 10.385 \\
\hline 10 & & 11.249 & 8.697 \\
\hline 12 & & 11.169 & 10.385 \\
\hline 14 & & 11.250 & 10.446 \\
\hline 18 & & 11.344 & 9.657 \\
\hline 20 & & 11.342 & 9.657 \\
\hline 21 & & 11.277 & 10.754 \\
\hline 23 & & 11.298 & 10.338 \\
\hline 26 & & 11.434 & 10.385 \\
\hline
\end{tabular}


R. Latha and J. Kanakaraj / American Journal of Applied Sciences 10 (8): 779-786, 2013

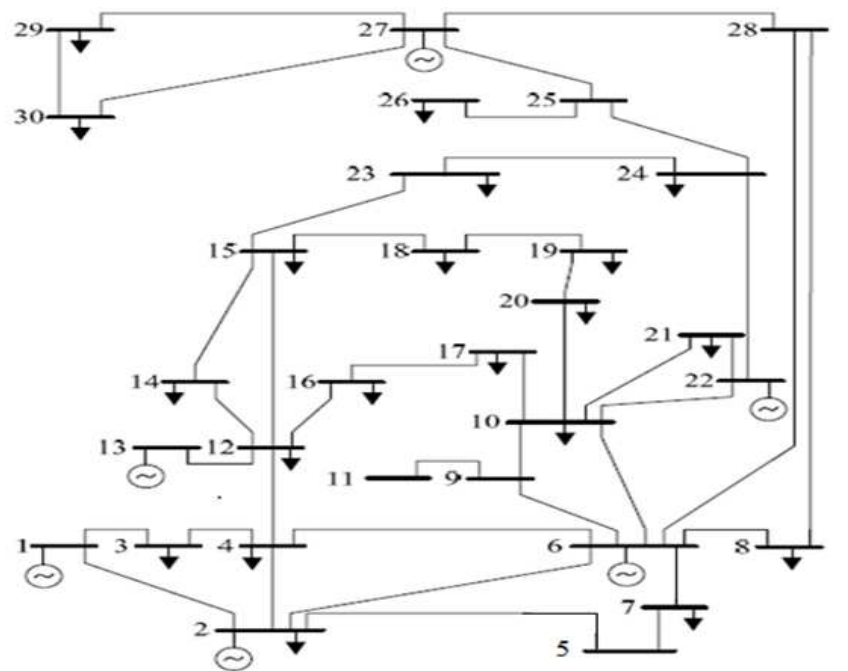

Fig. 3. Structure of IEEE-30 bus system

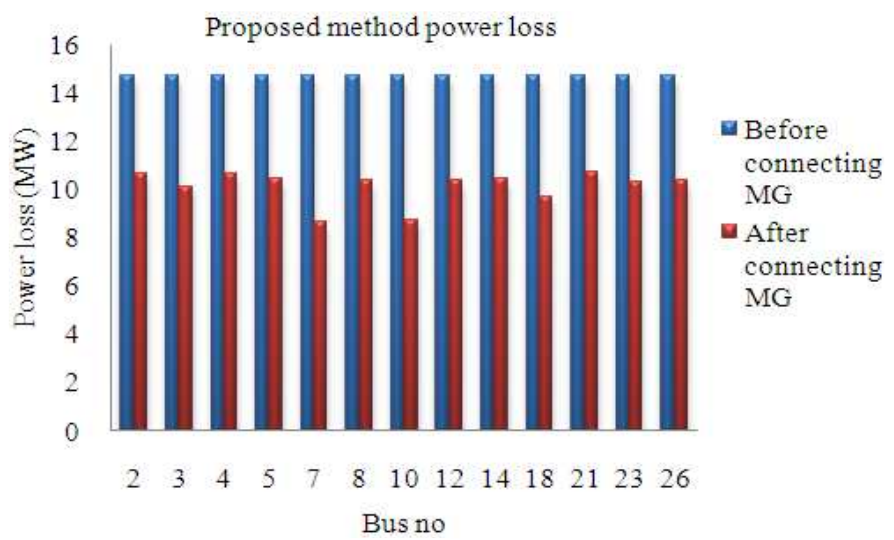

Fig. 4. Total power loss

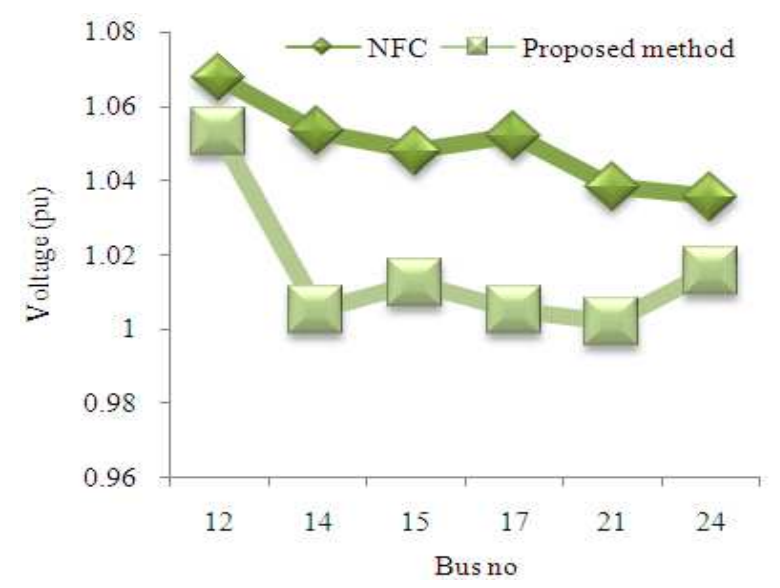

Fig. 5. Comparison of voltage stability between ANN method and proposed method

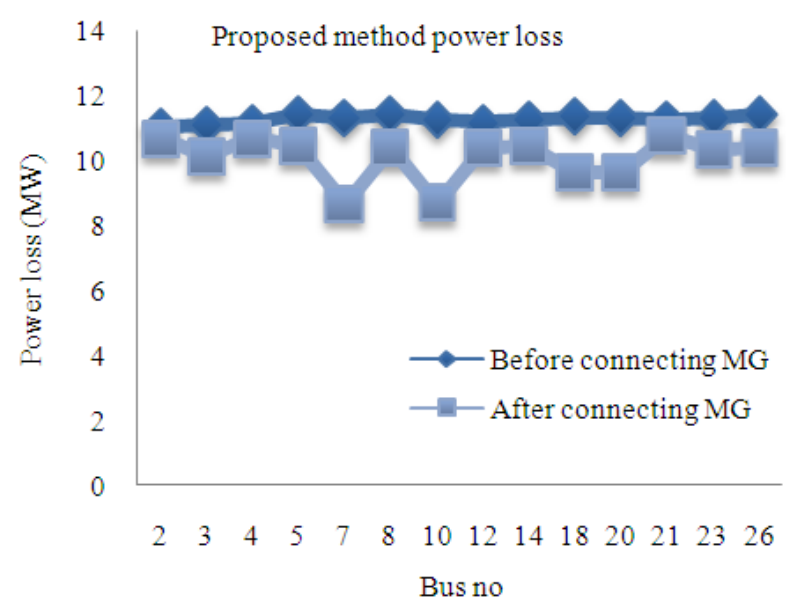

Fig. 6. Load bus power loss 


\section{CONCLUSION}

Microgrid is now commonly used in distribution systems to produce continuous power supply during abnormal condition and to reduce the total power losses in the system. This study presents an hybrid algorithm for connecting microgrid in a proper location in distribution systems, in order to minimize the power losses and to improve the voltage profile. The stability of the power system with distributed generations is maintained by both Adaptive Neuro-Fuzzy Inference System (ANFIS) and particle swarm optimization techniques presented in this study.

The effectiveness of the proposed method for stability enhancement has been tested on IEEE-30 bus system. In this study, PSO algorithm is used to find the suitable location to connect the microgrid and ANFIS approach is used to determine the optimum power capacity of the microgrid. From the time domain simulations and comparison results, it has been observed that using hybrid method, the voltage profile of the power system with microgrid has been improved and the real power losses also reduced by optimally fixing the microgrid in a power system. More reduction of power loss with modified hybrid approach is taken as a future work.

\section{REFERENCES}

Acharya, N., P. Mahat and N. Mithulnatha, 2006. An analytical approach for DG allocation in primary distribution network. Int. J. Elect. Power Energy Syst., 28: 669-679. DOI: 10.1016/j.ijepes.2006.02.013

Aref, A., M. Davoudi, A. Seifi, I. Ganjkhany and M. Davoudi, 2012. Particle Swarm Optimization based method for optimal placement and estimation of DG capacity in distribution networks. Int. J. Sci. Technol., 2: 486-491.

Attous, D.B. and Y. Labbi, 2009. Particle swarm optimization based optimal power flow for units with non-smooth fuel cost functions. Proceedings of the International Conference on Electrical and Electronics Engineering, Nov. 5-8, IEEE Xplore Press, Bursa, pp: 378-381.

Fraile-Ardanuy, J. and P.J. Zufiria, 2005. Adaptive power system stabilizer using ANFIS and genetic algorithms. Proceedings of the 44th IEEE Conference on Decision and Control and European Control Conference, Dec. 12-15, IEEE Xplore Press, pp: 8028-8033. DOI: 10.1109/CDC.2005.1583461
Hatziargyriou, N., H. Asano, R. Iravani and C. Marnay, 2007. Microgrids. IEEE Power Energy Mag., 5: 7894. DOI: 10.1109/MPAE.2007.376583

Jang, J.S.R., 1993. Adaptive-Network-Based Fuzzy Inference System (ANFIS). IEEE Trans. Syst. Man Cybernet., 23: 665-685. DOI: 10.1109/21.256541

Kalaivani, R. and V. Kamaraj, 2012. Enhancement of voltage stability by optimal location of SVC using genetic algorithm and particle swarm optimization. Am. J. Eng. Applied Sci., 5: 70-77. DOI: 10.3844/ajeassp.2012.70.77

Kayal, P. and C.K. Chanda, 2013. A simple and fast approach for allocation and size evaluation of distributed generation. Int. J. Energy Environ. Eng., 4: 2-9. DOI: 10.1186/2251-6832-4-7

Kothari, D.P. and I.J. Nagrath, 2006. Modern Power System Analysis. 2nd Edn., McGraw Hill, Dubuque, ISBN-10: 0073404551, pp: 694.

Lasseter, R.H. and P. Piagi, 2004. Microgrid: A conceptual solution. Proceedings of the IEEE 35th Annual Power Electronics Specialists Conference, Jun. 20-25, IEEE Xplore Press, pp: 20-25. DOI: 10.1109/PESC.2004.1354758

Lasseter, R.H. and P. Piagi, 2006. Control and design of microgrid components. University of Wisconsin.

Lasseter, R.H., 2011. Smart distribution: Coupled microgrids. IEEE Proc., 99: 1074-1082. DOI: 10.1109/JPROC.2011.2114630

Mashrei, M.A., 2012. Neural Network and Adaptive Neuro-Fuzzy Inference System Applied to Civil Engineering Problems. In: Fuzzy Inference SystemTheory and Applications, Azeem, M.F. (Ed.), ISBN10: 9535105251, pp: 472-490.

Rui, S., 2009. Voltage stability indices based on active power transfer using simulated phasor measurement. Ph.D. Thesis, Graduate School of Clemson University.

Singh, D., D. Singh and K.S. Verma, 2008. GA based energy loss minimization approach for optimal sizing \& placement of distributed generation. Int. J. Knowl. Based Intell. Eng. Syst., 12: 147-156. 